\title{
Doctor, builder, soldier, lawyer, teacher, dancer, shopkeeper, vet: exploratory study of which eleven-year olds would like to become a doctor
}

\author{
I. C. McManus ${ }^{1,2^{*}}$, Terry Ng-Knight ${ }^{1}$, Lucy Riglin ${ }^{1}$, Norah Frederickson ${ }^{1}$, Katherine Shelton ${ }^{3}$ and Frances Rice ${ }^{1}$
}

\begin{abstract}
Background: Very little is known about the extent to which eleven-year olds might consider a career in medicine. This exploratory study therefore asked children and their parents about medicine as a possible career, looking also at the relationship to a range of background measures.

Methods: A longitudinal, three-wave, questionnaire study of students transferring from primary to secondary school (STARS), with data collection at primary school (wave 1; mean age $11.3 \mathrm{yrs}$ ), in the first months of secondary school (wave 2; mean age $11.7 \mathrm{yrs}$ ) and at the end of the first year of secondary school (wave 3; mean age $12.3 \mathrm{yrs}$ ). Parents/carers also completed questionnaires. Children were entering ten large comprehensive secondary schools in the south-east of England; $46.3 \%$ were female, $15.6 \%$ receiving free-school meals, $39.8 \%$ were Black or Minority Ethnic and $28.8 \%$ had a first language which was not English. Of 2287 children in the study, 1936 children (84.5\%) completed at least one questionnaire of the three waves (waves 1, 2 and 3). The main outcome measures were an open-ended question in each wave, "What job would you like to do when you grow up?", and a more detailed questionnaire in wave 3 asking about 33 different jobs.
\end{abstract}

Results: $9.9 \%$ of children spontaneously mentioned medicine as a career on at least one occasion. For the specific jobs, would-be doctors particularly preferred Hospital Medicine, followed by Surgery, General Practice and then Psychiatry. Would-be doctors were also more interested in careers such as Nurse, Archaeologist, Lawyer and Teacher, and less interested in careers such as Shopkeeper, Sportsperson, or Actor/dancer/singer/musician. Would-be doctors were less Neurotic, more Open to Experience, more Conscientious, and preferred higher prestige occupations. Those interested in medicine did not score more highly on Key Stage 2 attainment tests or Cognitive Abilities Test, did not have a higher family income or greater parental/carer education, and did not have more experience of illness or deaths among family and friends.

Conclusions: An interest in a medical career, unlike high prestige jobs in general, is not associated with higher educational attainment or cognitive ability, and it is likely that only one in ten of the children interested in medical careers will have sufficient educational attainment at GCSE or A-level to be able to enter medical school.

Keywords: Medicine as a career, Children, Parents, 11-year olds, RIASEC, Occupational status

\footnotetext{
*Correspondence: i.mcmanus@ucl.ac.uk

${ }^{1}$ Research Department of Clinical, Educational and Health Psychology,

University College London, Gower Street, London WC1E 6BT, UK

${ }^{2}$ UCL Medical School, University College London, Gower Street, London

WC1E 6BT, UK

Full list of author information is available at the end of the article
}

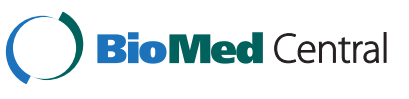

(c) 2015 McManus et al. Open Access This article is distributed under the terms of the Creative Commons Attribution 4.0 International License (http://creativecommons.org/licenses/by/4.0/), which permits unrestricted use, distribution, and reproduction in any medium, provided you give appropriate credit to the original author(s) and the source, provide a link to the Creative Commons license, and indicate if changes were made. The Creative Commons Public Domain Dedication waiver (http://creativecommons.org/publicdomain/zero/1.0/) applies to the data made available in this article, unless otherwise stated. 


\section{Background}

The study of medical student selection usually begins when candidates submit their applications to a medical school, which in the UK is via the Universities and Colleges Admissions Service (UCAS), when most applicants are about 17 years old. Occasional studies have involved students at the age of 16 who are considering applying to medical school [1]. Prior to that age, though, all seems to be silence. The impetus for the present study was the first wave of a longitudinal survey of UK ten-year olds who were asked the simple open-ended question, "What job would you like to do when you grow up?". Somewhat to our surprise, the answer 'doctor', or a related term such as 'surgeon' or 'GP', was given by nearly one in ten children (68/749; $9.1 \%)$. Since such a high proportion implies potential for widening participation, we took the opportunity in two later waves to ask more detailed questions.

This study asks how many 11 year-olds consider medicine as a possible career, and asks how that interest relates to other career interests, and to demographic, life event, educational and personality measures. The study was in large part exploratory, but the questions we asked are informed by studies of career choice in adolescents and adults. Careers were described in terms of the system of vocational preferences developed by Holland [2] who showed that career choices can be mapped into six types (RIASEC: Realistic, Investigative, Artistic, Social, Enterprising and Conventional) [3]. Gottfredson has suggested that children's career orientations change during development, younger children being primarily concerned with gender roles, while prestige becomes important during the ages 9 to 13, and specific fields of work, as characterised by RIASEC, become important from 14 onwards [4]. Whether the full RIASEC structure is present in children's career choices is still unclear [5-7], although there is a suggestion that 11-year olds have a similar Social, Investigative and Realistic axis as adults (which Prediger called People vs Things [8]), but that Enterprising, Conventional and Artistic interests differ from those of adults [9]. We therefore classified jobs using both RIASEC structure and prestige levels. RIASEC types are also associated with personality dimensions [10], and adult occupations also relate to childhood personality measures [11], and so personality was also investigated.

The selection of medical students in the UK has been of increasing interest in recent years $[12,13]$, particularly given interests in widening access, both in general and particularly in medicine. A concern, inevitably, is that some children, despite an interest in careers such as medicine, subsequently lose that interest or do not have that interest encouraged and nurtured. It therefore makes sense to try and look at interests in medical careers at a much earlier stage, and the transition to secondary education makes a good baseline for that assessment. The Medical Schools Council report, in particular, discusses widening participation by outreach work within secondary and primary schools [13]. The GMC sponsored research [12] also comments that, "most [widening access] activities target secondary school pupils, most often those aged 14-16 years. This is too late." (p.63, our emphasis). However neither report publishes any data on attitudes to medical careers in pupils below the age of about 14 .

\section{A note on education in England}

Compulsory education for children in the UK begins at age 5 (year 1), and there are differences between England, Scotland, Wales and Northern Ireland. The academic year runs from 1st September to 31st August. The present study took place in England, where primary education typically continues until year 6 (age 11). Children then move to secondary education in year 7 , taking GCSE (General Certificate of Secondary Education) exams in year 11 (age 15) and for more academic students, AS-level and A-level examinations are taken in years 12 (age 16) and 13 (age 17). Students typically enter university at age 18. School progress is assessed at various 'key stages' (KS), KS1 for years 1-2, KS2 for years 3-6, KS3 for years 7-9, KS4 for years 10-11 and KS5 for years 12-13. Assessments vary in type, sometimes being teacher assessments, sometimes being formal assessments, and sometimes being based on GCSE, AS and A-level examinations. In addition many schools and local authorities use tests such as the Cognitive Abilities Tests both to stream pupils, and also to allocate students to schools (where they are used to ensure diversity of ability ranges). Most state schools in England are comprehensive (and all of the schools in the present study are comprehensive), but there are also selective schools, both in the state and the private sector. For further information see https://www.gov.uk/government/collections/nationalcurriculum-assessments-test-frameworks.

\section{Methods}

The School Transition and Adjustment Research Study (STARS) (http://www.ucl.ac.uk/stars) is a longitudinal study of a large group of 11-year olds in their last year at primary schools (Year 6) in the south-east of England. The primary interest of STARS is in transitions, and how children respond to them, but the nature of the study means that there is potential for studying many other questions as well. The children were followed during the transition to secondary education, until the end of the first year at secondary school (Year 7) [14, 15]. The children entered ten large comprehensive (non-selective) schools in south-east England, an average of 205 children entering each school (range 120 to 290; SD 67). 
Questionnaires were given to Children (C), Parents/ Carers (P) and Teachers (T), C1, P1 and T1 being completed at the end of the final term of primary school, $\mathrm{C} 2$, P2 and T2 in the first term at secondary school, and C3, P3 and T3 at the end of Year 7 (May 2013) (see Table 1). Questionnaires were extensive, and only some items are described here. In particular there were measures of the Big Five personality scales [16], 21 items from the BFI (http://www.ocf.berkeley.edu/ johnlab/bfi.php) being completed by the parent/carer in P1. Schools provided background demographic measures, as well as measures of attainment at Key Stage 2 (KS2) and, where known, scores on the Cognitive Abilities Test (CAT) which is widely used in UK schools for selection, banding or prediction of likely attainment $[17,18]$. Seven of the ten schools also provided teacher assessments of Key Stage 3 (KS3) attainment for National Curriculum levels at the end of year 7, in English, Maths and Science. Scores vary from $2 c$, through $2 b, 2 a, 3 c, 3 b, 3 a$, etc., to $7 \mathrm{c}$ and $7 \mathrm{~b}$, and are scored from 1 to 17 , with an overall score calculated as an average (see https:// www.gov.uk/government/collections/national-curriculum-assessments-test-frameworks).

\section{Career measures}

In C1, C2 and C3 children were asked, "What job would you like to do when you grow up?", and in P1 and P2, parents/carers were asked, "What job would you like your child to do when they grow up?". Responses were free text, were transcribed into the computer, and subsequently coded by ICM into various categories (see below). In C3, children were also asked a more detailed question, "Here is a list of different jobs that people do. Say how much you might like to do each one by ticking one of the smiley faces next to it", with answers on a three-point scale (“): Would like it a lot" / "®: Not sure" / ": Wouldn't like it at all"). Thirty-three different jobs were presented, in alphabetical order. Four jobs were for different aspects of medicine (Surgeon, Hospital Doctor, GP and Psychiatrist). The remaining 29 jobs (see Table 2 ) broadly sampled the six RIASEC categories. Jobs were also sampled from high and low status occupations.
Scores on the six RIASEC scales for each job were obtained from the Occupation_Data and Interests files of O*NET 18.0 (http://www.onetcenter.org/db_releases.html), and are in the range 7 (high) to 1 (low). Prestige for each job was based on the Standard Occupational Classification 2000 (SOC2000) of the UK Office for National Statistics which varies from level 2 (Professional Occupations; $n=$ 16), $3(n=10), 4(n=1), 5(n=3), 6(n=2)$ and 7 (Sales and Customer Service Occupations; $n=1)$. Scores for RIASEC and prestige for each job are indicated in Table 2. For each child an average score on the six RIASEC scales and the prestige scale was calculated as the mean weighted preferences for the 29 nonmedical jobs. For ease of interpretation, SOC2000 scores were reversed so that high scores indicate high prestige. From the RIASEC scores we also calculated Prediger's [8] scales of People vs Things (2S + E-C-2R$\mathrm{I}+\mathrm{A})$ and Data vs Ideas (1.7E +1.7C -1.7I - 1.7A).

A checklist of 34 positive and negative life events in the previous year was provided in waves 1 and 3 for children and wave 1 for parents/carers, and we calculated composite scores for any report of death of family and friends, or of serious illness or injury among family, friends or the child themself.

Ethical approval for the study was obtained from the University College London Research Ethics Committee (ID number $=1522 / 01)$. Informed consent (parents/carers) and assent (children) was obtained from all participants.

Statistical analysis used SPSS 22.0. Differences between groups were compared using chi-square, Kendall's tau and t-tests as appropriate. Multivariate analysis used logistic regression with missing values substituted using the EM (expectation-maximisation) algorithm in SPSS.

\section{Results}

Of the children in the study, $46.3 \%(1058 / 2287)$ were female, $15.6 \%(274 / 1762)$ received free school meals, 39.8 \% (685/1723) were Black or Minority Ethnic (BME: Asian 389, Black 124, Mixed ethnicity 128, Other 44), and $28.8 \%(507 / 1763)$ had a first language which was not English (with differing denominators reflecting different response rates on the various questionnaires).

Table 1 "What job would you like to do when you grow up?" (child) or "what job would you like your child to do when they grow up?" (parent/carer)

\begin{tabular}{|c|c|c|c|c|}
\hline & \multicolumn{2}{|c|}{ Mean date of completion [mean age in years of child; SD] } & \multicolumn{2}{|c|}{ "Medicine" mentioned by: } \\
\hline & Child & Parent/Carer & Child & Parent/Carer \\
\hline Wave 1 & 28th May $2012[11.25 ; 293)$ & 26th May 2012 & $9.8 \%(68 / 695)$ & $7.5 \%(56 / 745)$ \\
\hline Wave 2 & 17th Nov $2012(11.72 ; 292)$ & 28th Oct 2012 & $12.8 \%(66 / 515)$ & $7.4 \%(40 / 544)$ \\
\hline Wave 3 & 15th Jun $2013(12.29 ; .295)$ & $\mathrm{n} / \mathrm{a}$ & $8.7 \%(111 / 1272)$ & $\mathrm{n} / \mathrm{a}$ \\
\hline \multicolumn{3}{|c|}{ Mentioned at any wave } & $9.8 \%(154 / 1564)$ & $9.7 \%(86 / 887)$ \\
\hline
\end{tabular}

Children were born between 1st September 2000 and 31st August 2001, and mean ages are given for children at various stages of the study. For parents the median date of completion of the questionnaire is given 
Table 2 Liking for different jobs for those who spontaneously mentioned ( $N=129)$ or did not mention $(N=1170)$ medicine on any of the open-ended questions ${ }^{a}$

\begin{tabular}{|c|c|c|c|c|c|c|c|}
\hline \multirow[t]{2}{*}{ RIASEC } & \multirow{2}{*}{$\begin{array}{l}\text { SOC } \\
2000\end{array}$} & & \multicolumn{2}{|c|}{ (-) Would like this job } & \multicolumn{2}{|c|}{ (-) Wouldn't like this job } & \multirow[t]{2}{*}{ Kendall's $\tau_{c}, P$} \\
\hline & & & $\begin{array}{l}\text { Medicine } \\
\text { mentioned }\end{array}$ & $\begin{array}{l}\text { Medicine not } \\
\text { mentioned }\end{array}$ & $\begin{array}{l}\text { Medicine } \\
\text { mentioned }\end{array}$ & $\begin{array}{l}\text { Medicine not } \\
\text { mentioned }\end{array}$ & \\
\hline \multicolumn{8}{|c|}{ Medical specialties } \\
\hline ISr & 2 & Hospital doctor & $84.5 \%(109)$ & $20.4 \%$ (239) & $3.9 \%(5)$ & $54.4 \%(636)$ & $.248, p<.001$ \\
\hline RIS & 2 & Surgeon & $46.5 \%(60)$ & $11.8 \%(138)$ & $32.6 \%(42)$ & $67.9 \%(795)$ & $.151, p<.001$ \\
\hline ISr & 2 & GP (General practitioner) & $36.4 \%(47)$ & $6.8 \%(80)$ & $37.2 \%(48)$ & $61.4 \%(718)$ & $.121, p<.001$ \\
\hline ISa & 2 & Psychiatrist & $21.7 \%(28)$ & $7.9 \%(93)$ & $46.5 \%(60)$ & $64.4 \%(753)$ & $.076, p<.001$ \\
\hline \multicolumn{8}{|c|}{ Other jobs } \\
\hline SIr & 3 & Nurse & $41.1 \%(53)$ & $12.9 \%(151)$ & $33.3 \%(43)$ & $65.4 \%(765)$ & $.135, p<.001$ \\
\hline Ir & 2 & Scientist & $52.7 \%(68)$ & $23.1 \%(270)$ & $24.0 \%(31)$ & $49.6 \%(580)$ & $.124, p<.001$ \\
\hline Eia & 2 & Lawyer & $48.1 \%(62)$ & $26.0 \%(304)$ & $22.5 \%(29)$ & $47.9 \%(560)$ & $.108, p<.001$ \\
\hline E & 2 & Businessperson & $50.4 \%(65)$ & $30.1 \%(352)$ & $20.9 \%(27)$ & $37.0 \%(433)$ & $.086, p<.001$ \\
\hline$C E$ & 2 & Accountant & $23.3 \%(30)$ & $11.3 \%(132)$ & $31.8 \%(41)$ & $45.6 \%(534)$ & $.067, p<.001$ \\
\hline IRa & 2 & Archaeologist & $24.8 \%(32)$ & $14.7 \%(172)$ & $41.1 \%(53)$ & $55.6 \%(651)$ & $.060, p=.001$ \\
\hline Aei & 3 & Journalist & $19.4 \%(25)$ & $17.9 \%(209)$ & $35.7 \%(46)$ & $54.2 \%(634)$ & $.057, p=.001$ \\
\hline IRc & 2 & Engineer & $36.4 \%(47)$ & $21.7 \%(254)$ & $42.6 \%(55)$ & $52.9 \%(619)$ & $.054, p=.004$ \\
\hline Sa & 2 & Teacher & $22.5 \%(29)$ & $21.5 \%(251)$ & $32.6 \%(42)$ & $47.2 \%(552)$ & $.043, p=.011$ \\
\hline Rci & 5 & Mechanic & $19.4 \%(25)$ & $13.4 \%(157)$ & $55.8 \%(72)$ & $63.7 \%(745)$ & $.032, p=.065$ \\
\hline IC & 2 & Computer programmer & $31.8 \%(41)$ & $25.8 \%(302)$ & $43.4 \%(56)$ & $49.0 \%(573)$ & $.026, p=.156$ \\
\hline ESC & 6 & $\begin{array}{l}\text { Air steward/Flight } \\
\text { attendant }\end{array}$ & $10.9 \%(14)$ & $10.2 \%(119)$ & $53.5 \%(69)$ & $59.7 \%(698)$ & $.021, p=.220$ \\
\hline $\mathrm{RCi}$ & 3 & Airline pilot & $19.4 \%(25)$ & $17.4 \%(204)$ & $54.3 \%(70)$ & $59.4 \%(695)$ & $.018, p=.294$ \\
\hline RE & 3 & Police officer & $31.0 \%(40)$ & $24.7 \%(289)$ & $45.0 \%(58)$ & $45.5 \%(532)$ & $.014, p=.462$ \\
\hline $\mathbb{R}$ & 2 & Vet & $18.6 \%(24)$ & $17.8 \%$ (208) & $52.7 \%(68)$ & $56.8 \%(665)$ & $.013, p=.435$ \\
\hline $\mathrm{Si}$ & 2 & Social worker & $14.0 \%(18)$ & $10.6 \%(124)$ & $62.8 \%(81)$ & $63.6 \%(744)$ & $.007, p=.680$ \\
\hline EC & 7 & Telephone salesperson & $2.3 \%(3)$ & $1.8 \%(21)$ & $85.3 \%(110)$ & $86.6 \%$ (1016) & $.006, p=.625$ \\
\hline$A R$ & 3 & Artist & $27.1 \%(35)$ & $29.2 \%(342)$ & $39.5 \%(51)$ & $41.3 \%(483)$ & $.000, p=.999$ \\
\hline $\mathrm{Ce}$ & 4 & Secretary & $9.3 \%(12)$ & $8.5 \%(99)$ & $62.8 \%(81)$ & $62.1 \%(727)$ & $-.001, p=.952$ \\
\hline Rc & 5 & Gardener & $3.1 \%(4)$ & $3.8 \%(45)$ & $79.8 \%(103)$ & 77.7 \% (909) & $-.008, p=.550$ \\
\hline $\mathrm{Ae}$ & 2 & Videogame designer & $34.9 \%(45)$ & $36.1 \%(422)$ & $48.8 \%(63)$ & $42.5 \%(497)$ & $-.017, p=.351$ \\
\hline (RE) & (3) & Soldier/Sailor/RAF & $17.1 \%(22)$ & $18.4 \%(215)$ & $65.1 \%(84)$ & $58.7 \%(687)$ & $-.021, p=.216$ \\
\hline ECs & 2 & Shopkeeper & $7.0 \%(9)$ & $8.4 \%(98)$ & $76.7 \%(99)$ & $68.5 \%(801)$ & $-.029, p=.050$ \\
\hline $\mathrm{AE}$ & 3 & Designer & $39.5 \%(51)$ & $45.2 \%(529)$ & $30.2 \%(39)$ & $23.1 \%(270)$ & $-.030, p=.107$ \\
\hline Reis & 6 & Hairdresser/barber & $10.9 \%(14)$ & $14.5 \%(170)$ & $71.3 \%(92)$ & $60.1 \%(703)$ & $-.040, p=.013$ \\
\hline $\operatorname{Re}$ & 3 & Sportsperson & $34.1 \%(44)$ & $43.9 \%(514)$ & $42.6 \%(55)$ & $34.4 \%(402)$ & $-.040, p=.026$ \\
\hline EA & 3 & Film producer/director & $34.1 \%(44)$ & $42.1 \%(492)$ & $34.1 \%(44)$ & $24.5 \%(287)$ & $-.041, p=.026$ \\
\hline R & 5 & Builder/decorator & $15.5 \%(20)$ & $18.3 \%(214)$ & $62.8 \%(81)$ & $49.7 \%(582)$ & $-.043, p=.014$ \\
\hline $\mathrm{Ae}$ & 2 & $\begin{array}{l}\text { Actor/dancer/ } \\
\text { singer/musician }\end{array}$ & $33.3 \%(43)$ & $46.3 \%(542)$ & $35.7 \%(46)$ & $26.5 \%(310)$ & $-.052, p=.004$ \\
\hline
\end{tabular}

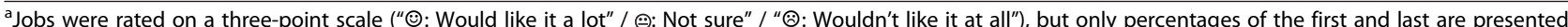
Kendall's tau $\left(\tau_{c}\right)$ is calculated using all three groups, and significant associations with $p<.05$ are shown in bold. Jobs were presented in alphabetical order in the questionnaire, but here are sorted by Kendall's tau. RIASEC codes are shown in size order, those greater than 5 in upper case and those between 4 and 5 in lower case. SOC2000 codes for occupational prestige are from 1 to 7 (but no $1 \mathrm{~s}$ were included). Note that Ns are slightly lower than in Table 1 due to not all children who had mentioned medicine answering the $\mathrm{C} 3$ questionnaire 
Mean gross family income was about $£ 37 \mathrm{~K}$ per annum, and $29 \%$ of children had at least one parent/carer with a degree. The percentage of non-white students at each school varied from $9.9 \%$ to $92.1 \%$ (mean $=64.7 \%$; median $=82.7 \%$; SD $=32.0 \%$ ). For state-maintained secondary schools in England in 2001, the average percentage of non-white students was $13 \%$, but there was a wide variation with many more non-white pupils in the South East of England [19].

In all three waves, children were asked the open-ended question, "What job would you like to do when you grow up?". Of 749 children in wave 1, 695 (92.8 \%) named a job, the remainder leaving the answer blank or saying "Don't Know". The total range was wide, including, for instance, "comic book artist", "hairdresser or something to with animals", "Lego designer", "mathematiciam and Part-time magician", "run my own Catery", "childminder like my mum" and "bounty hunter" (all spelling as in original). A number of common themes emerged however, and for wave 1 thirteen categories emerged which accounted for over half of the jobs named; medicine was at the top $(9.8 \%, 68 / 695)$. , followed by Actor/Dancer/Singer (59), Sportsperson (57), Teacher (51), Police Officer (31), Lawyer (26), Vet (24), Scientist (19), Engineer (17), Pilot (15), Computers/ Videogames (6), Nurse (5) and Childcare/Nursery (4), together accounting for $382(55.0 \%)$ of named jobs. Medicine was coded broadly, and responses varied from single, focussed responses, both generic ('A doctor'; 'Docter'), and specific ('Doctor GP'; 'Brain/Heart Surgeon"; 'Brian surgeon'; 'Pathologist'), to other cases where medicine was listed with other possible careers ('Doctor, singer'; 'I would like to be a pedetriton, a normal doctor or even a teacher who works in school'; 'Actor/singer/doctor/soldier/spy/footballer'); all were coded as indicating some interest in medicine. Openended responses in waves 2 and 3 showed the same pattern as in wave 1.

About $10 \%$ of children (and also parents/carers) spontaneously mentioned medicine or a related term as a job they would like to do (or like their child to do), in at least one of the waves (see Table 1). For children, mentioning medicine showed consistency across waves 1 and 2 (phi $=.517, p<.001), 1$ and 3 (phi $=.511, p<.001)$, and waves 2 and 3 (phi $=.432, p<.001$ ), as also did parents mentioning medicine in waves 1 and 2 (phi $=.342, p<.001)$. There was also a correlation between the child and the parent/carer mentioning medicine (phi $=.554, p<.001)$. Further analyses consider those $9.8 \%$ of children or those $9.7 \%$ of parents/carers who mentioned medicine on at least one wave.

In wave 3 , as well as being asked the open-ended question about jobs, children also rated their interest in 33 different jobs using a three-point scale (see Table 2).
Career preferences are often negative [20], people being more certain what they don't want to do than what they do want to do, and in these data children made a mean of 6.7 positive choices (SD 4.9) but 17.4 (SD 7.4) negative choices $(\mathrm{t}=35.5,1437 \mathrm{df}, p<.001)$.

Of the four medical categories the highest popularity was for Hospital Doctor with $24.3 \%$ (350/1438) saying they would like to do it, compared with $14.3 \%$ (206/ 1438) for Surgeon, $9.2 \%$ for GP (132/1438) and $8.9 \%$ (128/1438) for Psychiatrist. Table 2 shows how preferences for each specific career related to a child spontaneously mentioning medicine in the open-ended questions. 'Medicine' was mostly strongly related to 'Hospital doctor', then to 'Surgeon,' 'GP' and finally 'Psychiatrist', suggesting that the archetypical perception of medicine is as a hospital doctor. Those spontaneously choosing medicine also tended to choose Nurse, Scientist and other realistinvestigative careers such as Engineer and Archaeologist, but also Teacher, Journalist, Lawyer, Businessperson and Accountant. Those choosing medicine did not want to be a Shopkeeper, Hairdresser/Barber, Sportsperson, Film Producer/Director, Builder/Decorator or Actor/dancer/ singer/musician. There was no association of medicine with jobs such as Vet or Social Worker.

Table 3 shows the association of spontaneously mentioning medicine with a range of background measures. Amongst the demographic variables there are strong associations with being Black or Minority Ethnic, with not having English as a first language, and being female, but not with free school meals, family income or parental/carer education level. Forward-entry logistic regression found that both BME and not having English as a first language were both independent predictors of wanting to study medicine. School attainment measures showed no differences either at $\mathrm{KS} 2$, in the cognitive ability measures, or in the measures at KS3, between those who did and did not want to become doctors. There were however differences in personality, those wanting to be doctors being more conscientious, more open to experience and less neurotic. Those wanting to be doctors also showed differences in the other (nonmedical) job types that they preferred, being more interested in Investigative, Social, and Enterprising jobs, and less interested in Artistic or Conventional jobs. In addition, they were more likely to choose higher prestige jobs over lower prestige jobs.

The 25 variables in Table 3 were explored further using logistic regression, with missing values handled using the EM algorithm, and an alpha level of .001 to control for multiple testing. Five variables were statistically significant, an interest in medicine being predicted, in order of significance, by being more interested in high prestige jobs other than medicine, being non-white, 
Table 3 Association of spontaneously mentioning medicine with demographic, educational, personality and job type measures

\begin{tabular}{|c|c|c|c|}
\hline & Mentioned medicine & $\begin{array}{l}\text { Did not mention } \\
\text { medicine }\end{array}$ & Significance \\
\hline & Mean $(\mathrm{SD} ; \mathrm{N})$ or \% $(\mathrm{N})$ & Mean $(\mathrm{SD} ; \mathrm{N})$ or \% (N) & \\
\hline \multicolumn{4}{|l|}{ Demographic measures } \\
\hline Sex (\% Female) & $60.4 \%(154)$ & $47.2 \%(1410)$ & $\mathrm{Phi}=.079, \mathrm{X}^{2}=9.72,1 \mathrm{df}, p=.002$ \\
\hline Ethnicity (\% BME) & $74.8 \%(107)$ & $35.9 \%(1213)$ & $\mathrm{Phi}=.244 ; \mathrm{X}^{2}=80.5,1 \mathrm{df}, p<.001$ \\
\hline English not first language & $60.7 \%(145)$ & $26.2 \%(325)$ & $\mathrm{Phi}=.231, \mathrm{X}^{2}=73.7,1 \mathrm{df}, p<.001$ \\
\hline Free school meals & $14.5 \%(145)$ & $14.6 \%(1239)$ & Phi $=-.001 ; X^{2}=.002,1 \mathrm{df}, p=.968$ \\
\hline Family income (£000) & $33.1(22.6 ; 59)$ & $37.9(19.8 ; 510)$ & $\mathrm{t}=-1.70,567 \mathrm{df}, p=.091$ \\
\hline Parental education level & $2.43(1.09 ; 63)$ & $2.20(1.17 ; 570)$ & $\mathrm{t}=1.47,631 \mathrm{df}, p=.142$ \\
\hline \multicolumn{4}{|l|}{ Life events } \\
\hline Death of parent, brother, sister, grandparent or close friend & $20.8 \%(154)$ & $25.5 \%(1410)$ & Phi $=-.032, X^{2}=1.62,1 \mathrm{df}, p=.203$ \\
\hline Serious illness or injury in self, family or close friend & $24.7 \%(154)$ & $28.9 \%(1410)$ & Phi $=-.028, X^{2}=1.24,1 d f, p=.266$ \\
\hline \multicolumn{4}{|l|}{ School attainment } \\
\hline KS2 English & $4.35(.68 ; 139)$ & $4.26(.69 ; 1197)$ & $\mathrm{t}=1.36,1334 \mathrm{df}, p=.175$ \\
\hline KS2 maths & $4.41(.76 ; 139)$ & $4.30(.76 ; 1203)$ & $\mathrm{t}=1.72,1340 \mathrm{df}, p=.273$ \\
\hline Cognitive ability test; verbal & $101.7(13.0 ; 96)$ & $103.2(12.1 ; 869)$ & $\mathrm{t}=-1.17,963 \mathrm{df}, p=.244$ \\
\hline Cognitive ability test; non-verbal & $104.6(14.7 ; 96)$ & $102.3(13.8 ; 869)$ & $\mathrm{t}=1.53,963 \mathrm{df}, p=.127$ \\
\hline Cognitive ability test; quantitative & $103.9(14.4 ; 96)$ & $102.2(13.5 ; 869)$ & $\mathrm{t}=1.20,963 \mathrm{df}, p=.231$ \\
\hline KS3 (year 7) English & $10.70(2.36 ; 128)$ & $10.86(2.53 ; 1132)$ & $\mathrm{t}=-.675,1258 \mathrm{df}, p=.500$ \\
\hline KS3 (year 7) Maths & $11.94(2.75 ; 128)$ & $11.42(3.01 ; 1134)$ & $\mathrm{t}=1.89,1260 \mathrm{df}, p=. .060$ \\
\hline KS3 (year 7) Science & $11.43(2.13 ; 128)$ & $11.07(2.15 ; 1135)$ & $\mathrm{t}=1.84,1261 \mathrm{df}, p=067$ \\
\hline KS3 (year 7) average & $11.36(2.05 ; 128)$ & $11.11(2.28 ; 1135)$ & $\mathrm{t}=1.17,1261 \mathrm{df}, p=.241$ \\
\hline \multicolumn{4}{|l|}{ Personality } \\
\hline Neuroticism & $2.63(1.13 ; 76)$ & $3.02(1.07 ; 613)$ & $\mathrm{t}=-3.04,687 \mathrm{df}, p=.002$ \\
\hline Extraversion & $3.74(.77 ; 74)$ & $3.70(.85 ; 613)$ & $\mathrm{t}=.448,687 \mathrm{df}, p=.654$ \\
\hline Openness to experience & $4.37(.64 ; 76)$ & $4.14(.73 ; 614)$ & $\mathrm{t}=.2 .68,688 \mathrm{df}, p=.007$ \\
\hline Agreeableness & $4.45(.68 ; 76)$ & $4.30(.76 ; 615)$ & $\mathrm{t}=1.62,689 \mathrm{df}, p=.106$ \\
\hline Conscientiousness & $3.91(.75 ; 76)$ & $3.91(.75 ; 613)$ & $\mathrm{t}=2.81,687 \mathrm{df}, p=.005$ \\
\hline \multicolumn{4}{|l|}{ Job preferences } \\
\hline Preference for Realistic jobs (R) & $3.85(.17 ; 129)$ & $3.91(.20 ; 1170)$ & $t=-3.00,1297 d f, p=.003$ \\
\hline Preference for Investigative jobs (I) & $3.43(.19 ; 129)$ & $3.28(.20 ; 1170)$ & $\mathrm{t}=8.52,1297 \mathrm{df}, p<.001$ \\
\hline Preference for Artistic jobs (A) & $3.32(.21 ; 129)$ & $3.38(.24 ; 1170)$ & $\mathrm{t}=-2.73,1297 \mathrm{df}, p=.006$ \\
\hline Preference for Social jobs (S) & $3.07(.17 ; 129)$ & $3.03(.17 ; 1170)$ & $\mathrm{t}=1.93,1297 \mathrm{df}, p=.053$ \\
\hline Preference for Enterprising jobs (E) & $4.17(.13 ; 129)$ & $4.21(.14 ; 1170)$ & $t=-2.73,1297 d f, p=.006$ \\
\hline Preference for Conventional jobs (C) & $3.71(.14 ; 129)$ & $3.67(.15 ; 1170)$ & $\mathrm{t}=2.53,1297 \mathrm{df}, p=.011$ \\
\hline People (SAE) rather than Things (RIC) & $-1.22(.81 ; 129)$ & $-1.10(1.02 ; 1170)$ & $\mathrm{t}=-1.24,1297 \mathrm{df}, p=.216$ \\
\hline Data (CE) rather than Ideas (IA) & $1.92(.68 ; 129)$ & $2.08(.73 ; 1170)$ & $t=2.44,1297 d f, p=.015$ \\
\hline Preference for high prestige jobs & $1.30(.721 ; 121)$ & $.249(.856 ; 1124)$ & $\mathrm{t}=13.02,1243 \mathrm{df}, p<.001$ \\
\hline
\end{tabular}

being more open to experience, not being interested in Artistic careers, and being female, all with $p<.001$. Since the effects of ethnicity and sex were of particular interest, the seven interactions of sex and ethnicity with the other variables were tested but none reached a Bonferroni corrected significance level of 0.05/7.

\section{Discussion}

About one in ten eleven-year old children, when asked what job they would like to do when they grow up, spontaneously answer 'doctor', and they do so reliably across three separate occasions over a year. About one in ten of the children's parents/carers also spontaneously 
say that they would like their child to be a doctor, and that does not correlate with parental/carer levels of education. Although we know of no previous studies asking eleven-year old children whether they would like to become a doctor, the $B M J$ in 1946 did describe the results of an opinion poll which asked adults, "If you had a son [sic] starting out in life, what kind of work would you like him to take up?", to which $7.5 \%$ of respondents said medicine, a figure similar to the $9.7 \%$ found here [21].

Children wanting to be a doctor are more likely to be female and to come from ethnic minorities (and also not to have English as a first language), and in that sense they resemble medical students themselves, who are also more likely than the population to be female or from ethnic minorities. Compared with other schoolchildren, would-be doctors show different patterns of job interests, and are less interested in Holland's Artistic and Conventional groups of jobs and more interested in high prestige jobs (which more often are Investigative or Social). Those thinking of studying medicine are more open to experience, more conscientious and less neurotic than other children, the latter two characteristics, along with school attainment, being associated with an interest in higher prestige jobs in general, rather than medicine as such. Although there is some evidence that medical student specialty preferences are related to personal experience of illness [22, 23], there was no evidence that those wanting to be a doctor had more experience of illness or death.

Surprisingly, perhaps, given that medical students have some of the highest A-level grade attainments of any university applicants, there was no significant correlation of a preference for medicine as a career with school attainment, either with Key Stage 2 testing in year 6, or with the Cognitive Abilities Test (CAT) [17, 18]. CAT scores correlate very highly with GCSE attainment [24], and GCSEs in turn correlate highly with A-level grades [25]. A minimum attainment at GCSE and A-levels for having a chance of entering medical school is eight $A$ grades in the best 8 GCSEs, and three A grades at A-level, including an A in Chemistry. To achieve those GCSE grades (416 points, or an A at A-level Chemistry, would require about 121 or 117 points at $\mathrm{CAT}^{1}$. CAT scores of 117 and 131 would give 25 and $50 \%$ chances of an A grade in A-level Chemistry. Considering just the midpoint of those latter estimates (124), only $9.6 \%(9 / 96)$ of those wanting to study medicine had a CAT score on the quantitative scale of at least 124, and therefore had any reasonable chance of actually doing so given medical school entry criteria. The remaining $90 \%$ will probably therefore be disappointed in their aspirations. Amongst those not mentioning medicine at age 11, $5.0 \%$ (43/869) had quantitative CAT scores of 124 or more, and might of course at a later date choose to study medicine.
An interesting question is therefore why so many children (and their parents/carers) have what, it is sad to say, are probably unrealistic expectations. Although wanting to be a doctor does not correlate with academic attainment, children in the sample who wished to have higher prestige jobs in general have significantly higher KS2 and CAT scores, and their parents/carers have higher levels of education, suggesting that children mostly do realise that some jobs require higher attainment levels. Medicine though does not show that pattern, despite medical schools asking for attainment in the top 1 or $2 \%$ of the population, and academic attainment correlating with achievement at medical school [26]. One explanation may be that many people have experience of visiting doctors and hospitals (unlikely visiting lawyers or engineers), but few realise the technical and scientific underpinnings of the job, perhaps instead seeing what seems mainly to be a caring, intuitive task which could be carried out by many people.

An interesting question concerns the type of medicine in which children are interested. The detailed questions in $\mathrm{C} 3$, shown in Table 2, show clearly that it is hospital medicine and then surgery which are of the greatest interest, with a much lower proportion having an interest in General Practice. At a time when there is a national shortage of doctors interested in becoming GPs, that suggests that the lack of interest may have deeper origins.

Finally, is it reasonable to have made a decision to study medicine at the age of eleven? In the 1991 Cohort Study [27], one of us [ICM] asked entrants to medical school at what age they had first decided to study medicine and at what age they had definitely decided to study medicine. 44.7 \% (1323/2959) had first considered studying medicine by the age of eleven, but only $5.5 \%(164 /$ 2980) said they had definitely decided by that age. Of interest is that the gender and ethnic balance of those interested in medicine in our sample closely reflect the current medical student profile, suggesting that the pool from which medical students are drawn may be largely defined by 11 years? We will therefore be following the STARS cohort with great interest to find who actually does go on to study medicine.

\section{Study limitations}

This is a single study, although it is longitudinal and of a reasonable sample size, looking at entire populations within a number of schools. Care should therefore be taken in generalizing from its results.

\section{Conclusions}

About one in ten eleven-year olds spontaneously mentions medicine as a possible career, which has implications for widening diversity in medicine. Female students and 
minority ethnic students were more likely to mention medicine, and would-be doctors differed in personality and other careers which would be considered. There was no relationship between considering medicine as a career and performance on cognitive ability tests or school attainment measures.

\section{Endnotes}

${ }^{1}$ For general information on the Cognitive Abilities Test see http://www.gl-assessment.co.uk/products/catcognitive-abilities-test/performance-indicators. Detailed information on CAT and GCSEs is available at http:// www.gl-assessment.co.uk/sites/gl/files/images/Files/GC SE_Technical_Information.pdf and a spreadsheet is also available at http://www.docstoc.com/docs/163828315/ GCSE-Results-2012. A detailed Excel spreadsheet on the prediction of A-levels can be found at http:// www.gl-assessment.co.uk/sites/gl/files/images/Files/ For\%20Website\%20A\%20level\%20indicators\%20published\%20V2.xlsx.

\section{Competing interests}

The authors declare that they have no competing interests.

\section{Authors' contributions}

The STARS project was set up by FR, and she has overseen the project from its initiation, in particular steering questionnaire development, liaison with schools, and data collection. Data collection, data entry, data cleaning, and the preparation of derived and other variables was carried out by LR and TNK. FR, NF, KS and ICM have all contributed to aspects of the design and analysis of the STARS data. The idea of looking in detail at career interests in medicine was ICM's, but all authors contributed to the development of the more detailed questions for the C3 questionnaire. Statistical analysis was primarily by ICM. All authors have contributed to the final manuscript, and have approved it.

\section{Acknowledgements}

We are grateful to the children, the parents and carers, and the teachers who helped with this study, to the Nuffield Foundation for financial support, and to Lucy Brooks for administrative support on the project.

\section{Funding}

The STARS project has been funded by the Nuffield Foundation (www.nuffieldfoundation.org), but the views expressed are those of the authors and not necessarily those of the Foundation. The Foundation was not directly involved in study design, data collection or data analysis. The authors are independent of the funders.

\section{Author details}

${ }^{1}$ Research Department of Clinical, Educational and Health Psychology, University College London, Gower Street, London WC1E 6BT, UK. ${ }^{2}$ UCL Medical School, University College London, Gower Street, London WC1E 6BT, UK. ${ }^{3}$ School of Psychology, Cardiff University, Tower Building, 70 Park Place, Cardiff CF10 3AT, UK.

Received: 5 October 2014 Accepted: 16 October 2015

Published online: 04 November 2015

\section{References}

1. McManus IC, Livingston $\mathrm{G}$, Katona $\mathrm{C}$. The attractions of medicine: the generic motivations of medical school applicants in relation to demography, personality and achievement. BMC Med Educ. 2006;6:11.

2. Holland JL. Making vocational choices: A theory of careers. New York: Prentice Hall; 1973
3. Tracey TJ, Rounds J. Evaluating Holland's and Gati's vocational-interest models: a structural meta-analysis. Psychol Bull.

1993;100:229-46.

4. Gottfredson LS. Circumscription and compromise: a developmental theory of occupational aspirations. J of CP. 1981;28:545-79.

5. Bennett SJ. The development of vocational interests and abilities in secondary school-aged children (Unpublished PhD thesis). Plymouth: University of Plymouth; 2012.Available at https://pearl.plymouth.ac.uk/ bitstream/handle/10026.1//1232/2012Bennett748628Ph.D.pdf?sequence=1

6. Tracey TJG. The development of structure of interests in children: setting the stage. JVB. 2001;59:89-104.

7. Tracey TJG, Ward CC. The structure of children's interests and competence perceptions. J Couns Psychol. 1998;45:290-303.

8. Prediger DJ. Dimensions underlying Holland's Hexagon: missing link between interests and occupations? JVB. 1982;21:259-87.

9. Sodano SM. Integrating vocational interests, competencies, and interpersonal dispositions in middle school children. JVB. 2011;79:110-20.

10. Barrick MR, Mount MK, Gupta AK. Meta-analysis of the relationship between the five-factor model of personality and Holland'soccupational types. PP. 2003;56:45-74

11. Woods SA, Hampson SE. Predicting adult occupational environment from gender and childhood personality traits. J App Psych. 2010;95:1057.

12. Cleland J, Dowell J, McLachlan J, Nicholson S, Patterson F. Identifying best practice in the selection of medical students (literature review and interview survey). London: General Medical Council; 2012. http://www.gmc-uk.org/ Identifying_best_practice_in_the_selection_of_medical_students.pdf 51119804.pdf.

13. Medical Schools Council. Selecting for Excellence: Final Report. London: Medical Schools Council; 2014. http://www.medschools.ac.uk/ SiteCollectionDocuments/Selecting-for-Excellence-Final-Report.pdf.

14. Riglin L, Collishaw S, Shelton KH, McManus IC, Ng-Knight T, Sellers R et al:: Higher cognitive ability buffers stress-related depressive symptoms in adolescent girls. Development and Psychopathology, available on CJO2015. doi:10.1017/S0954579415000310.

15. Ng-Knight T, Shelton KH, McManus IC, Frederickson N, Rice F: Parental Influences on Self-Control at the Onset of Puberty. Poster presented at the International Convention of Psychological Science, March 2015, Amsterdam http://www.psychologicalscience.org/convention/icps_program/pdf/PosterSession-VIII.pdf

16. John OP, Srivastava S. The Big Five Trait Taxonomy: History, measurement, and theoretical perspectives. In: Pervin LA, John OP, editors. Handbook of Personality: Theory and Research. 2nd ed. New York: Guilford Press; 1999. p. 102-38.

17. Strand S. Comparing the predictive validity of reasoning tests and national end of Key Stage 2 tests: which tests are the 'best'? Br Educ Res J. 2006;32:209-25.

18. Calvin CM, Fernandes C, Smith P, Visscher PM, Deary IJ. Sex, intelligence and educational achievement in a national cohort of over 175,000 11-year-old schoolchildren in England. Intelligence. 2010;38:432.

19. Burgess S, Wilson D. Ethnic segregation in England's schools. London: London School of Economics, Centre for Analysis of Social Exclusion; 2004. Available at http://eprints.Ise.ac.uk/6313/1/Ethnic_Segretation_in_ England\%27s_Schools.pdf.

20. Rigby K. A concise scale for the assessment of attitudes towards institutional authority. Aust J Psychol. 1982;34:195-204.

21. Smyth $\mathrm{DH}$. Some principles in the selection of medical students. Brit Med J. 1946:2:357-67.

22. Crimlisk H, McManus IC. The effect of personal illness experience on career preference in medical students. Med Educ. 1987;21:464-7.

23. Woolf K, Cave J, McManus IC, Dacre JE. It gives you an understanding you can't get from any book. The relationship between medical students' and doctors' personal illness experiences and their performance: a qualitative and quantitative study. BMC Med Educ. 2007;7:50. doi:10.1186/1472-6920-7-50.

24. Deary IJ, Strand S, Smith P, Fernandes C. Intelligence and educational achievement. Intelligence. 2007;35:13-21.

25. McManus IC, Woolf K, Dacre J. The educational background and qualifications of UK medical students from ethnic minorities. BMC Med Educ. 2008:8:21. http://www.biomedcentral.com/ $1472-6920 / 8 / 21$ 
26. McManus IC, Woolf K, Dacre J, Paice E, Dewberry C. The academic backbone: Longitudinal continuities in educational achievement from secondary school and medical school to MRCP(UK) and the Specialist Register in UK medical students and doctors. BMC Med. 2013;11:242. doi:10.1186/1741-7015-11-242.

27. McManus IC, Richards P, Winder BC, Sproston KA, Styles V. Medical school applicants from ethnic minorities: identifying if and when they are disadvantaged. Brit Med J. 1995:310:496-500.

Submit your next manuscript to BioMed Central and take full advantage of:

- Convenient online submission

- Thorough peer review

- No space constraints or color figure charges

- Immediate publication on acceptance

- Inclusion in PubMed, CAS, Scopus and Google Scholar

- Research which is freely available for redistribution 